\title{
Fine needle Aspiration Cytology of various Head and Neck Swellings
}

\author{
Laxman Banstola ${ }^{1}$, Swasti Sharma ${ }^{2}$, Bijaya Gautam ${ }^{3}$
}

${ }^{1}$ Dr Laxman Banstola, Department of Pathology, Pokhara Academy of Health Sciences, Western Regional Hospital ${ }^{2}$ Dr Swasti Sharma, Department of ENT-HNS, Pokhara Academy of Health Sciences, Western Regional Hospital ${ }^{3}$ Dr Bijaya Gautam, Department of Biochemistry, Gandaki Medical College

\section{Correspondence:}

Dr. Laxman Banstola

Department of Pathology,

Pokhara Academy of Health Scieneces

Western Regional Hospital, Pokhara, Nepal

e-mail : Ibanstola@hotmail.com

Article recived : 3rd june 2018

Article accepted : 4th Oct. 2018

\begin{abstract}
Background: Head and neck swelling is a frequently encountered complaint in the outpatient department. A wide plethora of conditions give rise to head and neck lumps. Sometimes the diagnosis of these lesions is apparent from the site and associated features, while at other times the cause for mass in this region can be confusing. Fine needle aspiration cytology has emerged as a reliable tool for clinching the diagnosis in head and neck swellings.

Methods and Materials: A retrospective study was conducted in the department of Pathology, Pokhara Academy of Health Sciences, Western Regional Hospital, Pokhara. Details of diagnosed cases of $\mathrm{HN}$ swellings from the period of November 2015 to February 2018 were obtained from recorded data. Descriptive statistics was applied from the data collected for analysis.

Results: Out of total 456 patients included from a period of 28 months, female patients outnumbered male patients by 1.5 times. The most common age group of presentation for head and neck swellings was observed to be 20-29 years, with 93 patients which comprised of $20.39 \%$ of total. Highest incidence was that of lymph node swellings $(55.04 \%)$ followed by thyroid swellings $(21.49 \%)$.

Conclusion: Lymph node pathology was determined to be the commonest cause for head and neck mass. FNAC is a reliable and inexpensive means in investigating such lesions, which provides immense help in treatment of patients.
\end{abstract}

Keywords: Fine needle aspiration cytology, lymphadenitis, thyroid nodules, metastasis.

\section{INTRODUCTION}

Swelling in head and neck (HN) region is a very common presentation in the outpatient department. ${ }^{1}$, ${ }^{2}$ These lesions are quite routinely encountered by clinicians, in patients across all age groups. ${ }^{1} \mathrm{HN}$ swellings comprise a wide range of conditions. Swellings can arise from soft tissues, lymph nodes, thyroid gland, salivary glands, blood vessels, neural elements and lymphatic channels. ${ }^{3}$ Diagnosis range from reactive hyperplasia of lymph nodes to neoplasia. Lesions in the HN region can be broadly classified as developmental, inflammatory and neoplastic conditions. ${ }^{4}$ Site of the swelling and patient's age are important clues for differential diagnosis, among other parameters. The common pathologies encountered are lymphadenopathies, thyroid nodules (colloid nodules and goiter), thyroglossal cyst, salivary gland swellings (cysts, sialadenitis, adenomas and carcinomas) and lumps of skin appendages. ${ }^{2,5}$ The less common pathologies are carotid body tumour, cystic hygroma, branchial cyst, and pharyngeal pouch. ${ }^{2,5}$ Neoplasia is an important consideration in differential diagnosis because neck metastasis is often the first and the only presentation in neoplastic conditions.

The Annals of Surgery, in 1930 AD, first published a report on the usefulness of fine needle aspiration cytology as a diagnostic tool. ${ }^{6}$ At that time, not much attention was paid to the subject, since biopsy techniques were employed to obtain a diagnosis. But with time, it became clear that FNAC provided clinicians with accurate diagnosis, close to conventional biopsy. In this way, FNAC became established as an important 
procedure to confirm diagnosis in $\mathrm{HN}$ swellings.

FNAC is a simple, reliable and inexpensive diagnostic tool in evaluation of $\mathrm{HN}$ swellings..$^{7-9}$ It causes minimal trauma to the patient and carries virtually no risk of complications. ${ }^{10-14}$ It is an outdoor procedure which is safe and well accepted. ${ }^{3}$ It provides early differentiation of benign from malignant lumps. ${ }^{3}$ Surgery is avoided in non-neoplastic or inflammatory conditions with the help of FNAC report. ${ }^{3}$

This study was carried out to assess different $\mathrm{HN}$ swellings with cytological examination and to evaluate the utility of FNAC in diagnosis of HN swellings.

\section{MATERIALS AND METHODS}

An observational study was conducted in the department of Pathology, Pokhara Academy of Health Sciences (PAHS), Western Regional Hospital (WRH). Diagnosis of $\mathrm{HN}$ swellings from the period of November 2015 to February 2018 was obtained from recorded data. Other variables were also noted like age, sex of patients. Electronic database from the Department of Pathology was utilized for procuring the required data. All cases presenting to the department for FNAC were included. Apart from outpatient cases referred from various departments, those patients whose FNAC was carried out from different wards were also included. Cytological evaluation was performed and diagnosis from each case was based on cytomorphology, with correlation from clinical findings. In some cases, ultrasound-guided FNA material was requested.

Uniform approach was followed for obtaining aspirate. In all cases of $\mathrm{HN}$ swellings, first palpable mass was identified and was stabilized by digital palpation. The overlying skin was cleaned with alcohol swab. Aspiration in our setting was done with 21 gauge needle attached to a $10 \mathrm{ml}$ syringe. Multiple short excursions, with negative pressure maintained in the syringe, were made within the swelling and needle was withdrawn from the swelling after first releasing the negative pressure. The aspirated material was then smeared into glass slides with preparation of both air dried smears for Giemsa stain and 95\% alcohol fixed smears for Pap stain. Ziehl-Nelson stain was performed whenever required.

Finally, descriptive statistics was applied from the data collected for analysis. Demographic data and various diagnoses were projected after the analysis. Data analysis was achieved with Microsoft Excel.

\section{RESULT}

Our study included a total 456 patients from a period of 28 months. Female patients outnumbered male patients by 1.5 times. The most common age group of presentation for $\mathrm{HN}$ swelling in general was observed to be 20-29 years, with 93 patients which comprised of $20.39 \%$ of total. The next common group was 10 19 years with 86 patients $(18.85 \%)$. The distribution in various age groups is plotted in the line diagram, presented below. (Figure 1)

Figure1. Distribution of $\mathrm{HN}$ swellings among various age groups

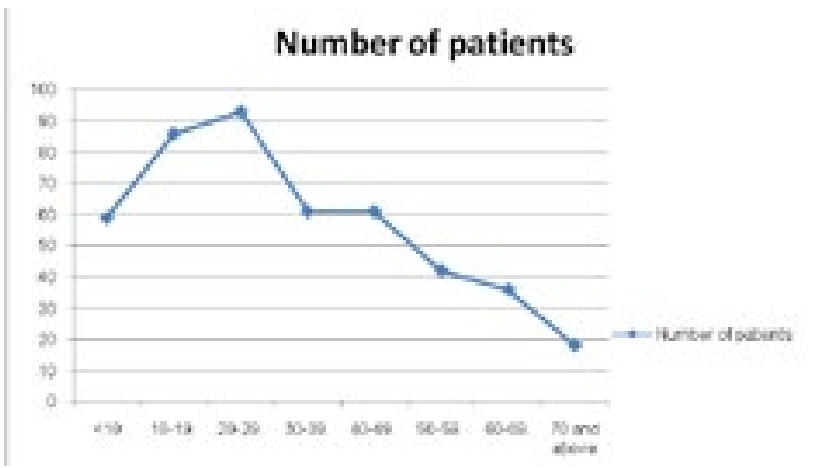

Table 1. HN swellings: organ-wise distribution

$\begin{array}{lll} & \text { Number } & \text { Percentage } \\ \text { Lymph node } & 251 & 55.04 \\ \text { Thyroid } & 98 & 21.49 \\ \text { Skin and subcutaneous tissue } & 53 & 11.62 \\ \text { Salivary glands } & 28 & 6.14 \\ \text { Miscellaneous } & 22 & 4.82\end{array}$

This study revealed that lymph node pathology was the most frequent category among various $\mathrm{HN}$ swellings. We diagnosed 251 cases of lymph node swellings which constitutes $55.04 \%$ of total cases. Thyroid swellings followed next with 98 cases comprising $21.49 \%$ of total cases enrolled. Thyroid pathology was classified according to Bethesda system of reporting. Accordingly, Category II included benign conditions, one of which is benign follicular nodule. The term benign follicular nodule encompasses adenomatoid nodule and colloid nodule. For the sake of uniformity, the term nodular goiter is applied in this study. Various other pathologies were skin and subcutaneous swellings with 53 cases $(11.62 \%)$, salivary gland swellings with 28 cases (6.14\%) and miscellaneous group with 22 cases $(4.82 \%)$. This is illustrated in Table

1. Table 2 displays the various pathologies observed in the total patients studied. 
Orginal Article Medical Journal of Pokhara Academy of Health Sciences (MJPAHS) Vol. 1 Issue 2 Jul-Dec 2018

Table 2. Various pathologies in Head and Neck Swellings

\begin{tabular}{|c|c|c|c|}
\hline & Diagnosis & $\mathrm{n}$ & $\%$ (Of total cases) \\
\hline \multirow[t]{7}{*}{ Lymph node } & Reactive lymphadenitis & 203 & 44.51 \\
\hline & Tubercular lymphadenitis & 25 & 5.48 \\
\hline & Granulomatous lymphadenitis & 8 & 1.75 \\
\hline & Metastatic SCC & 7 & 1.53 \\
\hline & Suppurative lymhadenitis & 5 & 1.09 \\
\hline & Non Hodgkin lymphoma & 2 & 0.43 \\
\hline & Hodgkin lymphoma & 1 & 0.21 \\
\hline
\end{tabular}

\begin{tabular}{|c|c|c|c|}
\hline \multirow[t]{6}{*}{ Thyroid } & Nodular goiter & 77 & 16.88 \\
\hline & Hashimoto thyroiditis & 8 & 1.75 \\
\hline & Suspicious for PTC & 7 & 1.53 \\
\hline & Papillary thyroid carcinoma & 3 & 0.65 \\
\hline & Suspicious for follicular neoplasm & 2 & 0.43 \\
\hline & Subacute thyroiditis & 1 & 0.21 \\
\hline
\end{tabular}

\begin{tabular}{ccc}
\hline Skin/subcutaneous tissue Epidermal cyst & 29 & 6.35 \\
Abscess & 22 & 4.82 \\
Lipoma & 2 & 0.43
\end{tabular}

\begin{tabular}{|ccc} 
Salivary glands Pleomorphic adenoma & 14 & 3.07 \\
\hline Chronic sialadenitits & 5 & 1.09 \\
\hline Sialadenosis & 4 & 0.87 \\
Acute sialadenitis & 2 & 0.43 \\
\hline Warthin's tumour & 2 & 0.43 \\
Mucoepidermoid carcinoma & 1 & 0.21
\end{tabular}

\begin{tabular}{|ccc|}
\hline Miscellaneous Benign cystic lesion & 14 & 3.07 \\
\hline Thyroglossal cyst & 4 & 0.87 \\
\hline Hemangioma & 2 & 0.43 \\
\hline Giant cell tumour of soft tissue origin & 1 & 0.21 \\
\hline Schwannoma & 1 & 0.21 \\
\hline Inadequate & & \\
Total & 4 & 0.87 \\
\hline & 456 &
\end{tabular}

Lymph node enlargements were the most common presentation among $\mathrm{HN}$ swellings. Reactive lymphadenitis constituted $80.86 \%$ of all lymph node swellings and $44.51 \%$ of all $\mathrm{HN}$ swellings. Tubercular lymphadenitis was seen in 25 cases. Seven cases of metastatic squamous cell carcinoma were detected. Two cases of non Hodgkin lymphoma were confirmed,while one case of lymphoma was found. (Table 3)
Table 3. Lymph node pathology

\begin{tabular}{|c|c|c|c|c|c|}
\hline \multirow[t]{2}{*}{ Benign } & \multicolumn{5}{|c|}{ Malignant } \\
\hline & $\mathrm{n}$ & $\%{ }^{*}$ & & $\mathrm{n}$ & $\%{ }^{*}$ \\
\hline Reactive lymphadenitis & 203 & 80.86 & Lymphoma & 1 & 39 \\
\hline \multirow[t]{2}{*}{ Tubercular lymphadenitis } & 25 & 9.96 & Non Hodgkin & 2 & 0.79 \\
\hline & \multicolumn{5}{|c|}{ lymphoma } \\
\hline Suppurative lymhadenitis & 5 & 1.99 & Metastatic SCC & 7 & 2.78 \\
\hline Granulomatous lymphadeniti & is 8 & 3.81 & & & \\
\hline
\end{tabular}

Among thyroid lesions, nodular goiter was the most common condition. Other benign diagnoses included Hashimoto's thyroiditis and subacute thyroiditis. Skin and subcutaneous swellings in $\mathrm{HN}$ region were confirmed as epidermal cyst in 29 cases, abscess in 22 cases and lipoma in two cases.Salivary gland lesions comprised 6.14 \%of all HN swellings. Miscellaneous cases included benign cystic lesion, hemangioma, giant cell tumour and schwannoma. (Table 3)

\section{DISCUSSION}

In this study, 456 patients of $\mathrm{HN}$ swellings were included who underwent FNAC. Relative frequencies of various pathologies presenting as neck swelling were calculated. Lymph node swellings were highest in frequency, accounting for $55.04 \%$ of all cases. Malignant conditions of lymph nodes were frequent in older age groups, except one which was detected in the third decade of life. Lymph node pathologies were the most frequently diagnosed conditions in other studies as well. ${ }^{1,15}$ Largest number of aspirates in a study by Khetrapal $S$ et al were from lymph nodes (64.1\%) among 290 patients, followed by thyroid lesions(16.9\%). ${ }^{1}$ Skin and soft tissue mass accounted for $14.1 \%$ of cases. Salivary gland lesions were detected in $4.1 \%$ cases. Out of total 290 patients, 268 (92.1\%) cases were non-neoplastic conditions, 21 cases were malignant and one case was inadequate for a definitive opinion. ${ }^{1}$

Next common pathology was that of thyroid lesions, which was observed in $21.49 \%$ of cases in our study. In some published literatures, thyroid nodules were the commonest cause for neck lumps. ${ }^{16}$ Nalini et al have concluded that neck swellings were largely thyroid lesions, 19 cases among the 40 patients studied, with only seven patients having lymph node pathology. ${ }^{16}$ Colloid goiter was the commonest lesion in thyroid swellings in the authors' study of 40 patients. The authors have outlined that 18 out of 19 cases of thyroid mass were benign lesions, while one was found 
to be malignant. Patel DN studied 250 patients of head and neck mass. ${ }^{3} 57$ cases of thyroid lesions were diagnosed, in which incidence of benign thyroid mass was $84 \%$. Six cases of thyroid mass were diagnosed as inflammatory lesions. Three patients had thyroid malignancy, one case each of medullary carcinoma, anaplasticcarcinoma and follicular carcinoma with metastasis.Female predominance was seen in patients of thyroid swellings. ${ }^{3}$

In this study, pleomorphic adenoma was the commonest diagnosis out of 28 salivary gland lesions.Among 14 patients of pleomorphic adenoma, nine were detected in the parotid gland, four in submandibular gland and one from the hard palate. In a similar study appraising the role of FNAC in HN swellings, authors have described that salivary gland lesions were found in 12 out of 250 patients, with 8 patients diagnosed as pleomorphic adenoma. ${ }^{3}$ Another study by Kapoor $S$ states that 15 out of 100 patients were diagnosed with salivary gland lesions. ${ }^{9}$ The most common benign tumour was pleomorphic adenoma $(60 \%)$, while $6.66 \%$ of 100 cases were found to have mucoepidermoid carcinoma. $^{9}$
Dholakia $A$ et al have described that they found 116 cases of soft tissue and miscellaneous lesions among 1063 patients. Epidermal cyst was the commonest condition among benign cystic lesions. Lipoma was the commonest lesion in benign soft tissue swellings. ${ }^{11}$ In four cases, no diagnosis could be reached in our study. These were labeled as inadequate for evaluation. We have analyzed that mostly these were swellings of very small size, swellings of cystic nature where cellular material was scanty and when aspirate consisted of hemorrhagic material.

\section{CONCLUSION}

Lymph node pathology (55.04\%) was the commonest diagnosis in $\mathrm{HN}$ swellings followed by thyroid lumps (21.49\%).FNAC is very reliable for investigating various swellings arising in head and neck region. Accurate diagnosis can be achieved, thereby eliminating the need for biopsy in most cases. It helps in planning of surgery for salivary gland lesions and thyroid nodules. Management of various lymph node conditions can be guided by FNAC.

\section{REFERENCES}

1. Khetrapal S, Jetley S, Jairajpuri Z, Rana S, Kohli S. FNAC of head and neck lesions and its utility in clinical diagnosis: a study of 290 cases. NJMR 2015 Jan-Mar; 5(1):33-8.

2. Poorey VK, Tyagi A. Accuracy of fine needle aspiration cytology in head and neck masses. Indian J Otolaryngol Head Neck Surg. 2014 Jun; 66(2): 182-6.

3. Patel DN, Patel PB, Patel HV, Gandhi TJ. Fine needle aspiration cytology role in head and neck lesions. IAIM. $2015 ; 2$ (8): 99-104.

4. Ishar T, Gupta RK, Khajuria A. Role of FNAC in diagnosis of non-thyroidal head and neck lesions. JK Science. 2012 Jan; 14(1): 9-13.

5. Goyal D. Study of cystic neck swellings over a period of 5 years. International Journal of Anatomy, Radiology and Surgery. 2015 Aprl 4(2):1-4.

6. Solanki PK, Patel AP, Taviad PP, Chaudhari VP, Patel SM. Fine needle aspiration cytology as a diagnostic procedure in head and neck swellings. Natl J Community Med.2012; 3(3):433-6.

7. Valiya LG, Padhariya BB, Baxi SN. Spectrum of FNAC in palpable head and neck lesions in a tertiary care hospital in Western India- a 2 years study. IOSR-JDMS. 2016 Jun; 15(6):14-9.

8. Vasilij A, Kativic SK. Fine needle aspiration cytology of head and neck lymph nodes in a ten-year period-single center experience. Acta Clin Croat. 2015; 54:315-8.

9. Kapoor S, Bagga PK, Rupesh S, Singh A, Kumar A, Singh H. Diagnostic accuracy of fine needle aspiration cytology in palpable lesions of head and neck in comparison to histopathology. IJCMR. 2015; 4(2): 449-53.

10. Singal P, Bal MS, Kharbanda J, Sethi PS. Efficacy of fine needle aspiration cytology in Head and Neck lesions.Int J Med and Dent Sci. 2014;3(2):421-30.

11. Dholakia A, Darad D, Vasavada D. Fine Needle Aspiration Cytology of Cervical Lymph Nodes:Our experience. Annals of Pathology and Laboratory Medicine. 2017 Jul-Aug;4(4):361-5.

12. Al-Qudehy ZA, Al-Mommen A, Al-Nufaily Y, Butt S. Appraising the role of fine needle aspiration cytology in non-thyroidal head and neck masses: a single referral institute experience. Otolaryngol. 2017.

13. Mitra P, Bharti R, Pandey MK. Role of fine needle aspiration cytology in head and neck lesions of paediatric age group. $\mathrm{J}$ Clin Diagn Res. 2013 Jun; 7(6): 1055-8.

14. Rathod GB, Parmer P. Fine needle aspiration cytology of swellings of head and neck region. Indian J Med Sci. 2012 Mar-april 66(3-4):49-54.

15. Thakur AS, Gahine R, Kulkarni V. Evaluation of fine needle aspiration cytology in the diagnosis of head and neck masses and its correlation with histopathological findings. Int J Adv Med. 2016;3(3):699-707.

16. Nallagutta N, Erugula RS, Gour S, Sameera A, Govada J, Kotikalapudi R. Fine needle aspiration of cervical lymph nodes: oue experience. Sch J App Med Sci. 2016 Nov;4(11B):3990-2. 